\title{
EFFECT OF TOTAL SURGICAL TIME ON PATIENT'S COMPLAINT OF MOUTH OPENING AFTER TRANSALVEOLAR REMOVAL OF IMPACTED MANDIBULAR WISDOM TEETH- A RANDOMISED, CONTROLLED, CLINICAL TRIAL
}

\author{
Naiya Pathak1, Dhara Shukla², Kalpita Shringarpure³, S. N. Goryawala 4 , Ashish Sachdeva5, Shivang Pathak ${ }^{6}$, Ritu Ojha ${ }^{7}$ \\ ${ }^{1}$ Assistant Professor, Department of Dentistry, GMERS Medical College and Hospital, Gotri, Vadodara, Gujarat, India. \\ ${ }^{2}$ Tutor, Department of Dentistry, GMERS Medical College and Hospital, Gotri, Vadodara, Gujarat, India. \\ ${ }_{3}^{3}$ Tutor, Department of Preventive and Social Medicine, Medical College Baroda, Vadodara, Gujarat, India. \\ 4 Professor and HOD, Department of Dentistry, GMERS Medical College and Hospital, Gotri, Vadodara, Gujarat, India. \\ ${ }^{5}$ Assistant Professor, Department of Surgery, GMERS Medical College and Hospital, Gotri, Vadodara, Gujarat, India. \\ ${ }^{6}$ Tutor, Department of Dentistry, GMERS Medical College and Hospital, Gotri, Vadodara, Gujarat, India. \\ ${ }^{7}$ Tutor, Department of Dentistry, GMERS Medical College and Hospital, Gotri, Vadodara, Gujarat, India.
}

\begin{abstract}
BACKGROUND

Trismus has a number of potential causes, the most common dental procedure leading to trismus is surgical removal of impacted wisdom tooth.

Aim- To study the effect of total surgical time on post-operative trismus, while removal of impacted lower wisdom teeth.

\section{MATERIALS AND METHODS}

This randomised, controlled, clinical trial was conducted as an open labelled study with allocation concealment at a tertiary care hospital for a period of eight months from September 2017 to April 2018. The patients were treated randomly with either physiodispenser or conventional rotary instrument using single block 1:1 allocation. Appropriate method for surgical removal of impacted mandibular wisdom teeth was performed. After this, the patients were divided into two groups according to total surgical time. Group A comprised of total surgical time of $\leq 15$ minutes and Group B comprised of total surgical time $>15$ minutes. Patients were called on first, third and seventh day for post-operative follow-up and data collection.
\end{abstract}

\section{RESULTS}

Total 70 patients were screened for the study. Out of these, 48 patients met with the inclusion criteria and were enrolled for the study. According to the total surgical time required for bone cutting, patients were divided into two groups. The total surgical time for Group A was less than or equal to 15 minutes $(n=18)$ and for Group B it was more than 15 minutes $(n=30)$. The most common type of tooth impaction noted was class II, position B (93.75\%). There was no statistically significant difference between the amount of trismus present between two groups on day $1(p=0.9)$. Similarly, on day 3 and day 7 also there was no significant difference noted in trismus in Group B (Total Surgical Time $>15$ mins) and Group A (Total Surgical Time $\leq 15 \mathrm{mins}$ ) ( $\mathrm{p}=0.3$ and 0.8 respectively).

\section{CONCLUSION}

This study found no statistically significant difference in post-operative trismus when compared, on the basis of total surgical time required for the transalveolar extraction of impacted mandibular third molar teeth.

\section{KEY WORDS}

Trismus, Impacted Third Molars, Total Surgical Time, Reduced Mouth Opening.

HOW TO CITE THIS ARTICLE: Pathak N, Shukla D, Shringarpure K, et al. Effect of total surgical time on patient's complaint of mouth opening after transalveolar removal of impacted mandibular wisdom teeth- a randomised, controlled, clinical trial. J. Evolution Med. Dent. Sci. 2018;7(48):5197-5202, DOI: 10.14260/jemds/2018/1153

\section{BACKGROUND}

The word trismus is derived from Greek word 'trismos' meaning gnashing and is defined as "prolonged tetanic spasm of the jaw muscles, by which normal opening of the mouth is restricted."[1]

'Financial or Other Competing Interest': None.

Submission 22-09-2018, Peer Review 06-11-2018,

Acceptance 13-11-2018, Published 26-11-2018.

Corresponding Author:

Dr. Dhara Shukla,

K-301, Vishranti Greens, Behind Narayan Gardens,

New Alkapuri, Gotri-390021,

Vadodara, Gujarat, India.

E-mail: researchdentistry11@gmail.com

DOI: $10.14260 /$ jemds/2018/1153

\section{(c) $(\mathbf{P})$}

Trismus has a number of potential causes, which range from the simple and non-progressive to those that are potentially life-threatening

These are infection, trauma, dental treatment, Temporomandibular Joint (TMJ) disorders, tumours and oral care, drugs, radiotherapy and chemotherapy, congenital problems and miscellaneous disorders.[1,2,3]

The most common dental treatment leading to trismus is surgical removal of impacted wisdom tooth. ${ }^{[3]}$ Also, it is well known that most of the times effect of trismus persist for five to seven days and at times more than a week after surgical removal of impacted wisdom tooth. ${ }^{[4]}$

Trismus may impair day-to-day activities like eating, speech, hygiene maintenance, affects facial appearance and may restrict access to dental procedures as well.[1] Studies evaluating the role of total surgical time on post-operative 
outcomes in general obstetric surgeries have shown variable results, while most of the studies on orthopaedic and plastic surgery have shown direct correlation of surgical time on post-operative complications. $[5,6,7]$

Most of the studies in oral and maxillofacial surgeries have shown that total surgical time has a direct influence on the post-operative outcomes such as pain, infection, healing, swelling etc. [8,9,10,11]

Most of the studies have evaluated trismus as a complication of removal of impacted third molar teeth, but very few studies have evaluated the co-relation of total surgical time and trismus. This study was undertaken to assess the influence of total surgical time on post-operative trismus after removal of impacted lower third molar.

\section{MATERIALS AND METHODS}

This randomised controlled clinical trial was conducted as an open labelled study with allocation concealment at a tertiary care hospital for a period of eight months from September 2017 to April 2018.

All patients aged 20 - 40 years visiting outpatient department of dentistry of this tertiary care hospital were included in the study with diagnosis of impacted mandibular third molar as Pell and Gregory classification class I/II with position B/C.[12] All patients requiring bone cutting during surgical extraction of impacted third molars were included.

Pregnant females, lactating mothers and medically compromised patients were excluded from this study. Also, patients with acute infection as well as those reluctant to give consent were not included.

The patients were treated randomly with either physiodispenser or conventional rotary instrument using single block 1: 1 allocation for simple randomisation done by a person independent of the study. Consecutively numbered and sealed envelopes were used for the same; later opened by investigator once patient gave consent for the study.

The surgical method for surgical removal of impacted mandibular wisdom teeth was performed for all patients by the same maxillofacial surgeon. Keeping all variables constant, the procedure was performed with a strict no touch technique. Patients received antibiotic coverage two days prior to the surgical procedure. Anaesthesia was given as local anaesthesia with lingual, buccal and inferior alveolar nerve block using 2\% lignocaine with 1: 80,000 adrenaline.

The conventional extended buccal incision was used for all patients followed by elevation of mucoperiosteal flap with Molt no 9 periosteal elevator. Bone cutting was done with buccal gutter technique using either physiodispenser (1500 rotations per minute, $35 \mathrm{~N} / \mathrm{cm}$ square) or traditional rotary instrument at 9 marking. The surgery followed after that as delivery of tooth, wound toilet, thorough irrigation and primary closure. At last pressure pack and post-operative instructions were given to the patients. All patients received a three days coverage of antibiotics and analgesics postoperatively same as used pre-operatively.

\section{Total Surgical Duration}

Total surgical duration was defined as duration of surgery from placement of incision upto the end of last suture. It was noted by assistant with the help of stopwatch in minutes.
Then patients were divided into two groups according to total surgical time. Group A comprised of total surgical time $\leq 15$ mins and Group B comprised of total surgical time $>15$ mins.

\section{Trismus}

Patients were called on first, third and seventh day for postoperative follow-up and data collection. The day of surgery was considered as day 0 . Trismus was assessed by measuring interincisal distance at mesial angle of incisal edge of upper and lower central incisors in mm pre-operatively and postoperatively by co-author at the maximum mouth opening with callipers. Considering $30-35 \mathrm{~mm}$ as normal mouth opening at incisal edge, trismus was considered as present at $\leq 25 \mathrm{~mm}$ of interincisal mouth opening.

\section{Sample Size Estimation}

Based on previous study, taking the least common of the complications the mean (SD) pain score on day 7 in control group using conventional rotary instrument was 4.11 (3.66) and that in the intervention group using physiodispenser instrument was 1.58 (2.45).[3] Taking $\alpha$ as 0.05 and power of the study $(\beta)$ as $80 \%$, sample size estimated using Open Epi software was 24 in each of the groups. Thus, the total sample size was $48 .[13]$

\section{Ethics}

All study patients were informed about the study and given a patient information sheet. Written and informed consent was obtained. The data obtained during the study was kept confidential and guidelines of declaration of Helsinki were followed. The study was conducted after approval of Local Ethics Committee.

\section{Data Management and Data Analysis}

Microsoft Excel Sheet (version 2010 with strict check files) was used to enter the data; once the forms were checked for errors and rectified for the same. These data were exported to Epi Info TM 7.2.2.6 software for analysis.

Gender and type of tooth impaction were analysed as percentages and proportions and association with total surgical duration was done using chi-square test. Age was reported as mean (SD); and the difference in age in the two groups was analysed using Independent t-test. Total time required for surgery (in minutes) and post-operative trismusinterincisal distance (in $\mathrm{mm}$ ) was reported as median (IQR). Presence/ absence of trismus in the two groups was assessed using chi-square. A $\mathrm{p}$ value of $\leq 0.05$ was considered statistically significant.

\section{RESULTS}

The study was conducted for a period of 8 months. Total 70 patients were screened for the study. Out of these, 22 patients were excluded. Five patients were excluded due to acute infection. Six patients were excluded due to type of impaction. Five patients were excluded due to being medically compromised. One patient was excluded due to pregnancy and five patients were excluded due to failure for follow-up for enrolment. Total 48 patients met with the inclusion criteria and were enrolled for the study. These patients were 
treated either with physiodispenser or conventional rotary instruments (Figure 1).

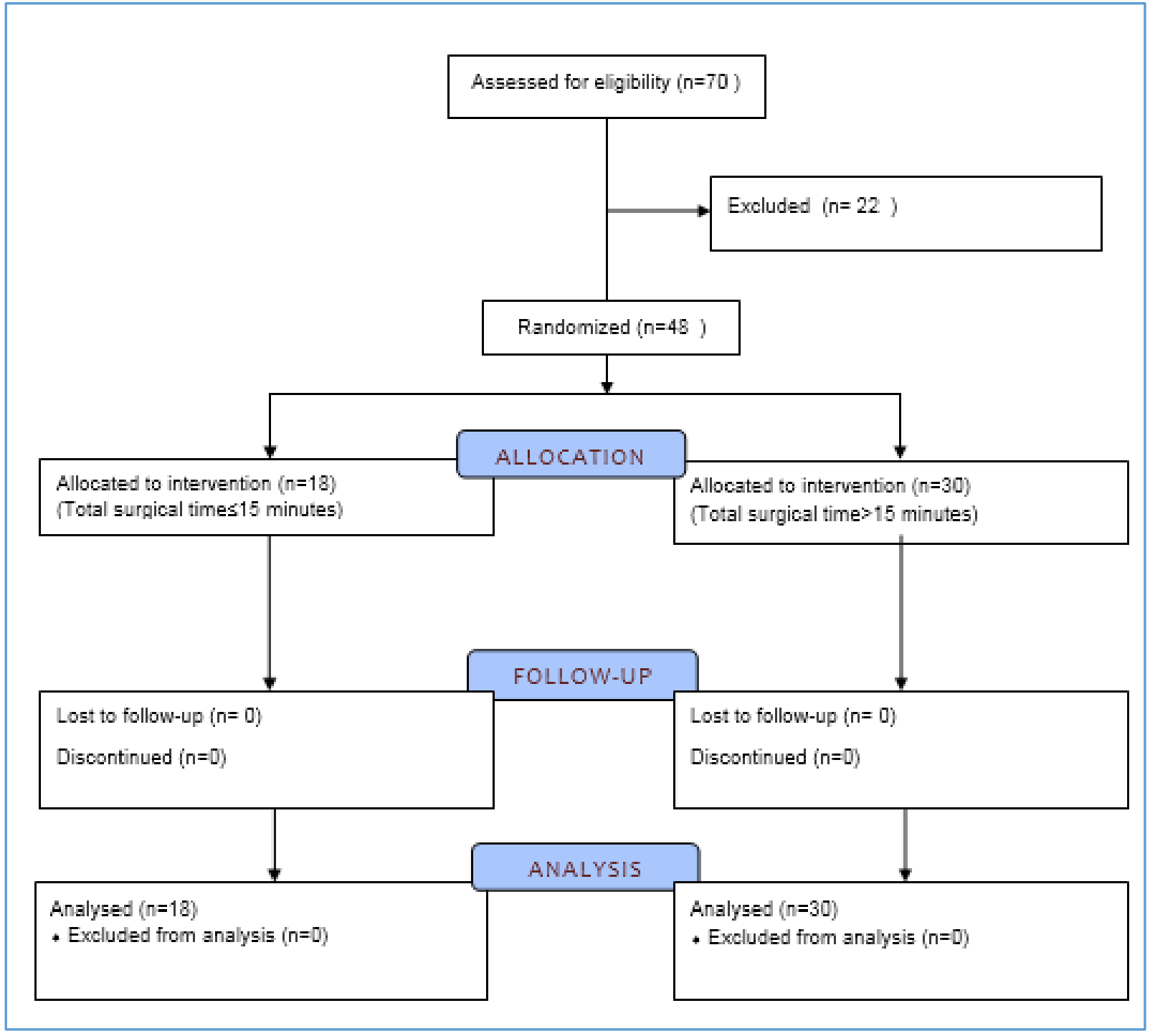

Figure 1. Patient's Allocation and Follow-Up in Groups A (Total Surgical Time $\leq 15$ mins) and $B$ (Total Surgical Time >15 mins)

According to the total surgical time required for bone cutting, patients were divided into two groups. The total surgical time for Group A was less or equal to 15 minutes; for Group B it was more than 15 minutes. Accordingly, 18 were enrolled in Group A and 30 in Group B (Figure 2). 


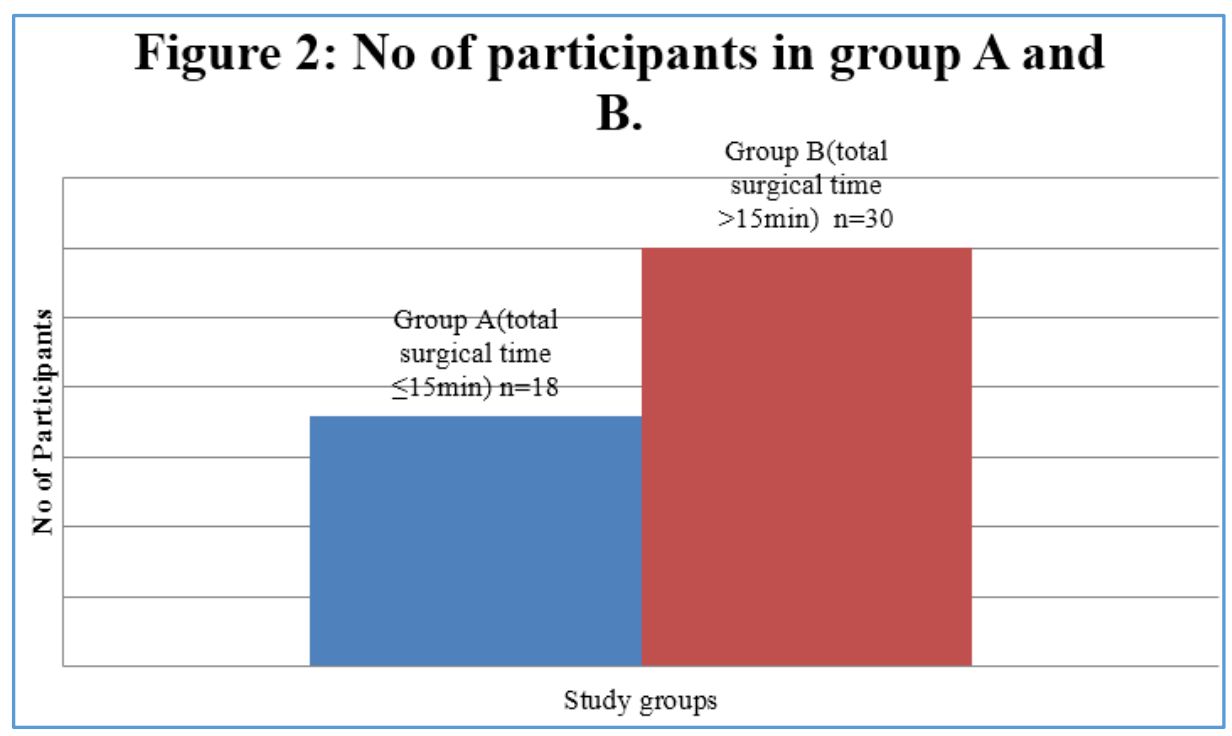

All the enrolled participants completed the required follow-up of three visits on day 1, day 3 and day 7 (Figure 1).

Table 1 shows age and gender distribution as well as type of tooth impaction of study population. The most common type of tooth impaction noted was class II, position B (93.75\%). Also two patients had class II position C and a patient had class III position C type of tooth impaction. For both these instances the total surgical time was more than 15 minutes.

\begin{tabular}{|c|c|c|c|c|}
\hline \multirow{2}{*}{\multicolumn{2}{|c|}{ Study Group }} & \multicolumn{2}{|c|}{\begin{tabular}{|l|} 
Study Participants (n), (N) \\
\end{tabular}} & \multirow[b]{2}{*}{ P value } \\
\hline & & $\begin{array}{c}\text { Group A }(\mathrm{n}=18) \text { (Total Surgical } \\
\text { Time } \leq 15 \text { mins) }\end{array}$ & $\begin{array}{c}\text { Group B }(n=30) \text { (Total Surgical } \\
\text { Time }>15 \text { mins) }\end{array}$ & \\
\hline \multicolumn{2}{|c|}{ Age (mean, SD) in years* } & \begin{tabular}{|l|}
$29.8(5.7)$ \\
\end{tabular} & $32.1(6.1)$ & $0.25^{*}$ \\
\hline \multirow{2}{*}{ Sex\# } & Male & $7(38.9)$ & $17(56.7)$ & \multirow{2}{*}{$0.08^{\#}$} \\
\hline & Female & $11(61.1)$ & $13(43.3)$ & \\
\hline \multirow{4}{*}{$\begin{array}{l}\text { Type of Tooth } \\
\text { Impaction** }\end{array}$} & Class 2 position $\mathrm{B}$ & $18(100)$ & $27(90)$ & \multirow{4}{*}{$0.26 \$$} \\
\hline & Class 2 position $\mathrm{c}$ & 0 & $2(6.67)$ & \\
\hline & Class 3 position $\mathrm{B}$ & 0 & 0 & \\
\hline & Class 3 position $\mathrm{c}$ & 0 & $1(3.33)$ & \\
\hline
\end{tabular}

Table 1. Baseline Data of participants of a Comparative Study of Effects of Total Surgical Duration on Post-Operative Trismus in patients treated with either Physiodispenser or Conventional Rotary Instrument

**Pell and Gregory Classification,[9] SD- Standard Deviation, $\mathrm{p} \leq 0.05$ was considered statistically significant. \#\$ Chi-square test, * Independent t-test.

Table 2 shows comparison of trismus present on the post-operative day 1, day 3 and day 7 between Group A (Total surgical time $\leq 15 \mathrm{mins}$ ) and Group B (total surgical time $>15 \mathrm{mins}$ ). There was no statistically significant difference between amount of trismus present between two groups on day $1(p=0.9)$. Similarly, on day 3 and day 7 also there was no significant decrease in trismus noted in Group B (total surgical time $>15$ mins) and in Group A (total surgical time $\leq 15$ mins) ( $p=0.3$ and 0.8 respectively).

\begin{tabular}{|c|c|c|c|c|}
\hline \multicolumn{2}{|c|}{ Outcome } & $\begin{array}{c}\text { Group A (n=18) (Total } \\
\text { Surgical Time } \leq 15 \text { mins) }\end{array}$ & $\begin{array}{c}\text { Group B }(n=30) \text { (Total Surgical } \\
\text { Time > } 15 \text { mins) }\end{array}$ & P value \\
\hline \multirow{3}{*}{$\begin{array}{c}\text { Trismus (Interincisal } \\
\text { distance } \leq 25 \mathrm{~mm} \text { ) }\end{array}$} & Day 1 & $13(72.2 \%)$ & $21(70 \%)$ & 0.9 \\
\hline & Day 3 & $7(38.8 \%)$ & $17(56.6 \%)$ & 0.3 \\
\hline & Day 7 & $4(22.2 \%)$ & $8(26.6 \%)$ & 0.8 \\
\hline
\end{tabular}

$\mathrm{P} \leq 0.05$ was considered statistically significant. Chi-square test.

\section{DISCUSSION}

Mouth opening is dependent on an intact co-ordinated sensory and motor neural activity of normal musculature and TMJ apparatus. The muscles primarily responsible for closing the mouth are temporalis, masseter and medial pterygoid.[1]

The normal range of mouth opening varies from patient to patient, within a range of $40-60 \mathrm{~mm}$, although some authors place the lower limit at $35 \mathrm{~mm}$. The width of the index finger at the nail bed is between 17 and $19 \mathrm{~mm}$. Thus, two fingers breadths $(40 \mathrm{~mm})$ upto three fingers' breadth (54-57 mm) is the usual width of opening. Mouth opening lesser than this is referred to as trismus.[1]

Evidence suggests that gender may be a factor in vertical mandibular opening. In general, males display greater mouth opening. [2] 
The aetiology of trismus may be classified as follows: infection; trauma; dental treatment; temporomandibular joint disorders; tumours and oral care; drugs; radiotherapy and chemotherapy; congenital problems; miscellaneous disorders. Amongst all these causes dental treatment, specially dentoalveolar surgeries is the most common cause of trismus.[2,3]

Just like pain and swelling, trismus is a post-surgical inflammatory response that involves the masticatory muscles. Overall, the complication rates post wisdom tooth surgery range from $2.6 \%$ to $30.9 \%$. Trismus being most common complication after alveolar osteitis.[8,11]

The inflammatory response involves both cellular and humoral immunity. Acute inflammation consists of changes that occur in minutes and stay for several hours or few days. Hence, trismus may persist for few days after surgical removal of impacted wisdom tooth.[10]

Because trismus is a very common complication of surgical removal of impacted wisdom teeth that persists for days post-surgery, it is important that clinicians become well versed with the probable parameters that may affect trismus.

Total surgical time has been postulated as a parameter affecting occurrence and severity of trismus after surgical removal of impacted wisdom teeth. Since, it is known that total surgical time does affect post-operative outcomes in general surgery. This study was undertaken to find out whether a direct co-relation exists between total surgical time and trismus in patients undergoing surgery for removal of impacted wisdom teeth.

Many studies have been done where assessment of trismus was done and its correlation with total surgical time evaluated. One such study showed direct co-relation between surgical time and trismus. Another finding of this study was trismus was less for teeth with conical morphology, whereas severity of trismus increased for teeth with more number of roots.[10]

The results of another study showed that trismus started to resolve on the second day after surgery in most of the patients, but there were some patients for whom trismus persisted even after seven days. The differences in this recovery rate is caused by various factors such as patient's immunity, medication consumption, the size of the trauma during surgery and the time spent for surgery.[11]

Another study on trismus stated that patients having mouth opening of less than $30 \mathrm{~mm}$ frequently had reduced oral quality of life than those who had more than $30 \mathrm{~mm}$ of mouth opening.[14]

A similar study stated that males usual lifestyle activities were resumed by four days after surgery, while difficulties due to trismus were resolved after five days post-surgery, but females had greater surgical time than males; average of 30 minutes; the resolution of trismus took a longer time than males.[15]

Consistent results were obtained using micromotor and piezosurgery; longer surgical time meant trismus persisted for more number of days; follow-up of trismus for this study was for 15 days.[16]

Another study stated that meticulous surgical techniques minimises total surgical time and hence severity of pain, swelling and trismus.[17] The results of another study concluded that patient related factors like older age, female gender and anxious patients are risk indicator for extended operation time and post-operative complication like trismus and pain.[18] The result of another study stated that skill of surgeon and surgical time greater than 30 minutes are risk factors for trismus.[19] In another study, it was found that duration of surgery and not flap design influence postoperative trismus.[20]

In our study, we had divided patients into two groups: Group A consisted of patients in whom total surgical time was less than or equal to 15 minutes and Group B consisted of patients in whom surgical time was greater than 15 minutes. Assessment of trismus was done pre-operatively and then on day 1, 3 and 7 post surgery.

The results of our study state that there was no statistically significant difference in post-operative trismus for both the groups on day 1 , day 3 and day 7 . Our results are not concurrent to the results of previous studies. This may be attributed to the post-operative physiotherapy jaw exercises done by the patients. Jaw exercises may have played a role in trismus recovery even in patients with longer surgical time. Also in this study, we have used two different types of instruments; conventional rotary and physiodispenser. This may have attributed to the variation in results.

Longer operative time is an independent risk factor that can be partially modified to reduce the occurrence or severity of trismus in patients undergoing surgical removal of lower impacted wisdom teeth. Some factors affecting surgical time are modifiable, while others are not. Some of the modifiable parameters that can impact operative time are pre-operative planning, surgeon experience, surgeon fatigue, operative room staff experience and access to equipment. Hence, all possible attempts must be made to ensure that these factors are optimised to reduce the total surgical time. This can ensure that probability of post-operative trismus are minimum, thereby improving post-operative quality of life of patients undergoing surgical removal of impacted wisdom teeth.

\section{CONCLUSION}

This study found no statistically significant difference in postoperative trismus when compared on the basis of total surgical time required for the transalveolar extraction of impacted mandibular third molar teeth.

\section{REFERENCES}

[1] Dhanrajani PJ, Jonaidel O. Trismus: aetiology, differential diagnosis and treatment. Dental update 2002;29(2):88-92, 94.

[2] Poornima G, Poornima C. Trismus. Journal of health Science Research 2004;5(2):15-20.

[3] Yuasa H, Sugiura M. Clinical postoperative findings after removal of impacted mandibular third molars: prediction of postoperative facial swelling and pain based on preoperative variables. British Journal of Oral and Maxillofacial Surgery 2004;42(3):209-14.

[4] Paul CK, Rahman QB, Alam S, et al. Effect of age on immediate post-operative tissue reaction following extraction of impacted mandibular third molar. BSMMU J 2014;7(2):120-8. 
[5] Ren-Shi MA, Gui-Shan GU, Cheng-Xue WANG. Relationship between surgical time and postoperative complications in senile patients with hip fractures. Chinese Journal of Traumatology 2010;13(3):167-72.

[6] Catanzarite T, Saha S, Pilecki MA, et al. Longer operative time during benign laparoscopic and robotic hysterectomy is associated with increased 30-day perioperative complications. J Minim Invasive Gynecol 2015;22(6):1049-58.

[7] Hardy KL, Davis KE, Constantine RS, et al. The impact of operative time on complications after plastic surgery: a multivariate regression analysis of 1753 cases. Aesthetic Surgery Journal 2014;34(4):614-22.

[8] Bui CH, Seldin EB, Dodson TB. Types, frequencies and risk factors for complications after third molar extraction. J Oral Maxillofac Surg 2003;61(12):137989.

[9] Anyanechi CE, Saheeb BD. The complications associated with the extraction of asymptomatic impacted mandibular third molars: a prospective clinical study of 63 patients. Journal of Neurology and Neuroscience 2016;7(98):1-5.

[10] Farshid A, Mohiti AK, Ghasemzadeh O. Prevalence and risk factors for complications of mandibular third molar surgery. American Journal of Oral and Maxillofacial Surgery 2015;3(1)43-52.

[11] Marwan AR, Syamsudin E, Karasutisna T. The infrared radiation effect to the trismus recovery after odontectomy. Padjadjaran Journal of Dentistry 2007;19(3):90-6.

[12] Juodzbalys G, Daugela P. Mandibular third molar impaction: review of literature and a proposal of a classification. J Oral Maxillofac Res 2013;4(2):e1.
[13] Azam K, Hussain A, Maqsood A, et al. Effects of surgery duration on post-extraction sequelae following impacted third molar surgery by using two different bone cutting methods: a double blind randomized trial. Pakistan Oral \& Dental Journal 2016;36(1):8-13.

[14] Phillips C, White RP, Shugars DA, et al. Risk factors associated with prolonged recovery and delayed healing after third molar surgery. J Oral Maxillofac Surg 2003;61(12):1436-48.

[15] Mistry FK, Hegde ND, Hegde MN. Postsurgical consequences in lower third molar surgical extraction using micromotor and piezosurgery. Annals of Maxillofacial Surgery 2016;6(2):251-9.

[16] Sisk AL, Hammer WB, Shelton DW, et al. Complications following removal of impacted third molars: the role of the experience of the surgeon. Journal of Oral and Maxillofacial Surgery 1986;44(11):855-9.

[17] Benediktsdottir LS, Wenzel A, Petersen JK. Mandibular third molar removal: risk indicators for extended operation time, postoperative pain and complications. Oral Surg Oral Med Oral Pathol Oral Radiol Endod 2004;97(4):438-46.

[18] Grossi GB, Maiorana C, Garramone RA, et al. Assessing postoperative discomfort after third molar surgery: a prospective study. J Oral Maxillofac Surg 2007;65(5):901-17.

[19] Mobilio N, Vecchiatini R, Vasquez M, et al. Effect of flap design and duration of surgery on acute postoperative symptoms and signs after extraction of lower third molars: a randomized prospective study. Journal of Dental Research, Dental Clinical, Dental Prospects 2017;11(3):156-60.

[20] Cheng H, Chen BP, Soleas LM, et al. Prolonged operative duration increases risk of surgical site infections: a systematic review. Surgical infections (Larchmt) 2017;18(6):722-35. 